\title{
IMPACT OF FAMILY LEVEL FACTORS ON ALCOHOL DRINKING IN PRIMARY SCHOOL CHILDREN
}

\author{
Veronika Rehorčíková1, Eva Nemčovská1, Zuzana Sklenárová1, Andrej Kállay², Daniela Kállayová1, Alexandra \\ Bražinová1, Miriam Slaná ${ }^{2}$ \\ 'Department of Public Health, Faculty of Health Sciences and Social Work, Trnava University, Trnava, Slovakia \\ ${ }^{2}$ Department of Social Work, Faculty of Health Sciences and Social Work, Trnava University, Trnava, Slovakia
}

\begin{abstract}
SUMMARY
Objective: The aim of our study was to identify and analyze selected factors influencing alcohol use among primary school children aged 8 to15 years in the academic year 2009/10.

Methods: The sample consisted of children from 28 primary schools. Data of this cross-sectional study were collected using questionnaires. Chi-Square test was used to test differences in proportions of observed phenomena between boys and girls. Multiple logistic regression analysis was performed to identify the influence of selected factors on the variable "child's alcohol drinking per week".

Results: The sample consisted of 2,494 respondents ( $52 \%$ of boys, $48 \%$ of girls). In the study group $78 \%$ of all respondents $(95 \% \mathrm{Cl}=76-80$ ) drank alcohol infrequently (less than once a week) or did not drink alcohol at all, and $22 \%$ of respondents ( $95 \% \mathrm{Cl}=20-24$ ) drank alcohol at least once a week.

More boys than girls considered alcoholic beverages such as beer, wine and spirit as quite easily available. We performed the model of multivariate logistic regression analysis using the independent variables: age of respondents, gender of respondents, mother's alcohol drinking, father's alcohol drinking, sibling's alcohol drinking, parental rules, parental control, and mental support from parents (if their children have problems) to identify their effect on the dependent variable - child's alcohol drinking per week. We found out that mother's alcohol drinking and a lack of mental support from parents did not have a statistically significant influence on child's alcohol drinking per week.

Conclusion: The results of our study point to the fact that it is necessary to focus on the prevention of alcohol drinking in general and among school children in particular. We recommend greater control of the sale of alcoholic beverages, so as to prevent the purchase by people under 18 years of age.
\end{abstract}

Key words: alcohol drinking, primary school children, risk factors, parents, alcoholic beverages, public health

Address for correspondence: V. Rehorčíková, Department of Public Health, Faculty of Health Care and Social Work, Trnava University, Univerzitné námestie 1, 91843 Trnava, Slovakia. E-mail: veronika.rehorcikova@truni.sk

\section{INTRODUCTION}

In recent decades, many social, political and economic changes have taken place facilitating implementation of interventions in the field of medicine and public health. They caused the change of the profile of young people's health throughout the world. At the forefront of negative social, behavioural and environmental factors hazardous to health are smoking, alcohol consumption and drug use (1). The World Health Organization (WHO) warns that alcohol drinking among young people is now becoming a growing public health problem in many countries. Its harmful effect - mainly the loss of self-control increases the risk of accidents (including traffic), violence (domestic violence) and early death (2). Nowadays, children are exposed to drugs at a younger age and the prevention should therefore start in the primary school (3). Children are interested especially in drugs that are easily accessible to them - financially, culturally or otherwise - such as alcohol, tobacco or medicaments. Alcohol occupies the prominent position amongst psychoactive substances with milder effects compared to other drugs. The addiction develops gradually, but its excessive consumption tends to be more dangerous than "hard drugs" (4). In Slovakia, the surveys about drug use in children are predominantly carried out in schools, due to the fact that the school survey is a key indicator usually investigated at the national level in all European Union Member States (5). The results of the Slovak survey 1 TAD - Tobacco, Alcohol, Drugs in children aged 11 to 14 years showed that in comparison with the 1994 figures, there was a decrease in the percentage of excessive drinkers in the family, nevertheless, since 2002 it has still represented about one fifth of adults. Consumption of beer and wine remained at about the same level, but the consumption of spirits has increased (6). Youths, therefore, rank amongst the most vulnerable population with regard to protection against drugs and drug abuse. Children aged 8 to 15 years acquire many skills and habits they could observe within their families. Thus, it is important to know which preventable factors can affect the substance abuse. In the Slovak Republic, there are not many surveys targeting primary school children. Therefore, the aim of our study was to identify and analyze selected factors influencing alcohol abuse among primary school children aged 8 to 15 years in the academic year 2009/10. 


\section{MATERIALS AND METHODS}

\section{Characteristics of the Sample}

This study was based on the project entitled "Cross-sectional study of attitudes, habits and awareness about drugs among primary school children aged 8 to 15 years in Slovakia in the school year 2009/10" and it was one of the projects supported by the grant of the Slovak Government to promote the anti-drug activities.

Locations for selecting primary school children were determined using the Global Youth Tobacco Survey (GYTS) methodology (7). The number of schools in different regions of Slovakia was taken into account as well as their population and a number of children. In the second phase, within these schools, the third - nine grade classes were selected randomly. The sample consisted of children from 28 primary schools situated in towns and villages from all parts of Slovakia. The total number of respondents was 2,538. After subsequent cleaning of data in the database, 2,494 respondents $(98 \%)$ were included to conduct comprehensive analysis. This selection methodology applies the principle of external validity. This constitutes a representative sample of the population of Slovakia.

\section{Method of Data Collection}

Data of this cross-sectional study were collected from 31 May 2010 to 11 June 2010 using questionnaires. The children filled in the questionnaires anonymously, without the presence of their teacher. Before completing questionnaires, respondents were instructed about the importance of the study and the confidentiality of data processing. Used questionnaires were based on proven tools created by the European Monitoring Centre for Drugs and Drug Addiction (EMCDDA).

\section{Statistical Analysis}

We used Chi-Square test to test differences in proportions of observed phenomena between boys and girls. The statistic analysis was carried out using the R-project (open source statistical software). Confidence interval for all results was 95\%. Multiple logistic regression analysis was performed to identify the influence of selected factors on the variable "child's alcohol drinking per week" and thus established: the regression coefficient, value of OR (Odds Ratio) and 95\% confidence interval. To establish the optimal logistic regression model, we used backward selection method, where at first we included all independent variables into the model. Consequently, we excluded the variables that did not have a statistically significant effect on the dependent variable - "child's alcohol drinking per week", and then we repeated the analysis.

The type of variables used for the model of logistic regression was similar to the one used in the study of Marcinkova et al. "Socioeconomic predictors of smoking behaviour among school-aged children in Slovakia", nevertheless, there was a need for several modifications, because of the specificity of the alcohol abuse (8).

\section{RESULTS}

The sample consisted of 2,494 respondents. In terms of gender representation there were more boys (52\%) than girls (48\%). The median age of respondents was 13 years (I.Q=12, III.Q=14). Minimum age was 10 years and maximum 15 years.

In the study group $78 \%$ of all respondents $(95 \% \mathrm{CI}=76-80)$ drank alcohol infrequently (less than once a week) or did not drink alcohol at all, and $22 \%$ of respondents $(95 \% \mathrm{CI}=20-24)$ drank alcohol at least once a week.

There was no statistically significant difference in alcohol drinking per week between boys and girls (Table 1).

In our study group, we also examined the experiences of respondents with the accessibility of selected alcoholic beverages. Their perceptions of the accessibility differed by gender. More boys than girls considered alcoholic beverages such as beer, wine and spirit quite easily accessible. The differences were confirmed as statistically significant (Table 2).

The next step of data analysis was to perform the model of multivariate logistic regression analysis using the independent continuous variable age of respondents and categorical: gender of respondents, mother's alcohol drinking, father's alcohol drinking, sibling's alcohol drinking, parental rules, parental control, and mental support from parents (if their children have problems) to identify their effect on the dependent variable - "child's alcohol drinking per week" (respondents who did not drink alcohol during the week $=0$, respondents who drank alcohol at least once a week $=1$ ).

We found out that mother's alcohol drinking and a lack of the psychological support from parents did not have a statistically significant influence on the child's alcohol drinking per week. We did not include the above mentioned non-significant variables into the final regression model and we repeated the analysis. The results are shown in Table 3.

\section{DISCUSSION}

The United Nations Office on Drugs and Crime (UNODC) reported that the use of alcohol, tobacco and other drugs among young people is increasing in most countries and several studies focus on the prevalence and causes of the substance use (9). Several authors indicate that the differences between boys and girls as regards alcohol drinking are continuously diminishing (10-12) and show an alarming number of alcohol intoxication in children $(11,13-15)$. This fact can be confirmed by the results of our study as well, because there was no statistically significant difference between boys and girls in frequency of alcohol drinking per week. According to the international study "Health Behaviour in School-aged Children (HBSC)" carried out in 2005-2006, the prevalence of alcohol consumption in the countries involved in this study varied. Among 11 years old respondents who drank

Table 1. Comparing the experiences with alcohol drinking per week between boys and girls in the sample $(n=2,494), 2010$

\begin{tabular}{|l|c|c|c|c|c|}
\hline $\begin{array}{l}\text { Alcohol drinking } \\
\text { per week }\end{array}$ & Gender & abs. & $\%$ & $95 \% \mathrm{Cl}$ & \multirow{2}{*}{ p value } \\
\hline \multirow{2}{*}{ Never } & boys & 1,010 & 78 & $75-80$ & \multirow{2}{*}{ NS } \\
\cline { 2 - 5 } & girls & 937 & 79 & $76-81$ & \\
\hline \multirow{2}{*}{$\begin{array}{l}\text { At least 1 time } \\
\text { a week * }\end{array}$} & boys & 293 & 22 & $20-25$ & \multirow{2}{*}{ NS } \\
\cline { 2 - 5 } & girls & 254 & 21 & $19-24$ & \\
\hline
\end{tabular}

*Volume of wine glass was $0.2 \mathrm{I}$, beer glass $0.5 \mathrm{I}$ and spirits $5 \mathrm{cl}$. 
Table 2. Comparing the experiences with the availability of selected alcoholic beverages between boys and girls in the sample $(n=2,494), 2010$

\begin{tabular}{|c|c|c|c|c|c|c|c|c|c|c|c|}
\hline \multirow{2}{*}{$\begin{array}{l}\text { Alcoholic } \\
\text { beverages }\end{array}$} & \multirow{2}{*}{ Gender } & \multicolumn{3}{|c|}{ Quite easy available } & \multicolumn{3}{|c|}{ Quite difficult } & \multicolumn{3}{|c|}{ Can't judge } & \multirow{2}{*}{$\mathrm{p}$ value } \\
\hline & & abs. & $\%$ & $95 \% \mathrm{Cl}$ & abs. & $\%$ & $95 \% \mathrm{Cl}$ & abs. & $\%$ & $95 \% \mathrm{Cl}$ & \\
\hline \multirow{2}{*}{ Beer } & boys & 970 & 74 & $72-77$ & 177 & 14 & $12-16$ & 156 & 12 & $10-14$ & \multirow{2}{*}{$<0.001$} \\
\hline & girls & 813 & 68 & $66-71$ & 218 & 18 & $16-21$ & 160 & 14 & $12-16$ & \\
\hline \multirow{2}{*}{ Wine } & boys & 801 & 61 & $59-64$ & 312 & 24 & $22-26$ & 190 & 15 & $13-17$ & \multirow{2}{*}{$<0.001$} \\
\hline & girls & 605 & 51 & $48-54$ & 407 & 34 & $31-37$ & 179 & 15 & $13-17$ & \\
\hline \multirow{2}{*}{ Spirit } & boys & 561 & 43 & $40-46$ & 507 & 39 & $36-42$ & 235 & 18 & $16-20$ & \multirow{2}{*}{$<0.001$} \\
\hline & girls & 375 & 31 & $29-34$ & 602 & 51 & $48-53$ & 214 & 18 & $16-20$ & \\
\hline
\end{tabular}

Table 3. Results of the repeated multivariate logistic regression analysis selected independent variables on child's alcohol drinking per week

\begin{tabular}{|c|c|c|c|c|c|}
\hline \multicolumn{2}{|l|}{ Independent variables } & \multirow{2}{*}{$\frac{\beta}{0.37}$} & \multirow{2}{*}{$\frac{\mathrm{OR}}{1.45}$} & \multirow{2}{*}{$\frac{95 \% \mathrm{Cl}}{1.31-1.61}$} & \multirow{2}{*}{$\begin{array}{l}\mathrm{p} \text { value } \\
<0.001\end{array}$} \\
\hline Age of respondents & & & & & \\
\hline \multirow[t]{2}{*}{ Gender } & boys (ref.) & & 1 & & \\
\hline & girls & -0.30 & 0.74 & $0.56-0.98$ & $<0.05$ \\
\hline \multirow[t]{3}{*}{ Father's alcohol drinking } & never (ref.) & & 1 & & \\
\hline & every day & 0.80 & 2.23 & $1.19-4.18$ & $<0.05$ \\
\hline & sometimes & 0.44 & 1.55 & $1.12-2.16$ & $<0.01$ \\
\hline \multirow[t]{3}{*}{ Sibling's alcohol drinking } & never (ref.) & & 1 & & \\
\hline & every day & 1.47 & 4.37 & $1.78-10.69$ & $<0.01$ \\
\hline & sometimes & 0.70 & 2.01 & $1.50-2.69$ & $<0.001$ \\
\hline \multirow[t]{2}{*}{ Parental rules } & yes (ref.) & & 1 & & \\
\hline & no & 0.54 & 1.71 & $1.20-2.44$ & $<0.01$ \\
\hline \multirow[t]{2}{*}{ Parental control } & yes (ref.) & & 1 & & \\
\hline & no & 0.92 & 2.50 & $1.84-3.41$ & $<0.001$ \\
\hline
\end{tabular}

alcohol at least once a week dominated boys over girls, but among 13 years old respondents in Spain dominated girls (7\%) over boys (6\%). Similarly, among 15 years old respondents in Greece dominated girls (13\%) over boys (11\%) (16). It should be noted that compared to other countries in the HBSC study, 11 years old respondents from Slovakia exceeded the average of alcohol drinking at least once a week (17). In our study group at least $22 \%$ of boys $(95 \% \mathrm{CI}=20-25)$ and $21 \%$ of girls $(95 \% \mathrm{CI}=19-24)$ drank alcohol once a week.

The Ministry of Health in Australia in its publication "Teenagers and Alcohol: A Guide for Parents" focused on the prevention of alcoholism in children. The publication points out that the discussion in families about the effects of alcohol consumption on health should begin before children reach the age of ten - eleven years. Children are more susceptible to this information in the early age, since they need to know what parents expect (18). However, in Slovak families frequency of this discussion could be influenced by the fact that there is a strong tradition of local drinking of alcoholic beverages, which include mainly spirits and wine (19). The relatively easy accessibility of wine was also mentioned by respondents in our study group, but as for girls it was confirmed that spirits are quite difficult to access. Overall, our group experienced relatively easy accessibility of beer.

The authors of several studies indicate that the older children are, the higher chance there is for them to drink alcohol $(13,20)$.
Specifically, in our study group the chance increased 1.45 times (95\% CI $=1.31-1.61)$. In the families where one of the parents is drinking alcohol, the risk of alcohol drinking in children also increases (20-22). Wong et al. stated that in children younger than 14 years who had a parent addicted to alcohol the risk of alcohol abuse increased compared to the control group (23). In our study group, if the father drank alcohol every day, the chance to drink alcohol weekly increased in children 2.23 times $(95 \%$ $\mathrm{CI}=1.19-4.18)$. Several authors indicate that a statistically significantly higher number of children drank alcohol if not controlled by their parents and if their parents were not taking care in what activities they engaged in during their leisure time when compared with the control group (23-25). In our respondents, these aspects of parental control were confirmed to be very important as well, otherwise the chance to drink alcohol increased 2.5 times $(95 \%$ $\mathrm{CI}=1.84-3.41)$.

Authors of several studies have also identified alcohol drinking among peers or friends as another very important factor in the context of alcohol drinking among children $(26,27)$. The results of another study point to the fact that if siblings drank alcohol, there was a significantly increased chance of respondent's alcohol abuse (24). In our study group, if respondents had siblings who drank alcohol every day, there was a chance of their alcohol abuse 4.37 times higher ( $95 \% \mathrm{CI}=1.78-10.69)$. Ando et al. also found that girls are more sensitive to this factor than boys (27). 
However, there are some possible limits to our study. One of them may be due to the comparison of our findings with the results of other studies, as these studies might examine different frequency of alcohol use among respondents. Because of the questionnaire method of data collection, there might be possible bias due to falsely answered questions. Some respondents might feel ashamed to answer that they have been drinking alcohol, even despite the questionnaires being anonymous and completed without teacher supervision.

\section{CONCLUSION}

The results of our study point to the fact that it is necessary to focus on the prevention of alcohol drinking among youth. Given the relatively high number of respondents who reported experiences with the relatively easy accessibility of alcoholic beverages, we recommend greater controls of the sale of alcoholic beverages to persons under 18 years of age. The next step could be collaboration with school psychologists on distribution of the results of our study and also the use of results for developing preventive programmes for the schools. We are also going to extend this type of survey to high schools and compare the results with other foreign studies. Another possibility to continue our research could be exploring associations between alcohol drinking and marihuana use at high schools according to the study of Csémy, Sovinová and Prochádzka "Alcohol consumption and marihuana use in young adult Czechs" (28).

\section{Acknowledgements}

We would like to thank school authorities, teachers and primary school children for their collaboration. The authors would like to acknowledge Dr. Monica O'Mullane, PhD., for English-language proofing of the original manuscript.

\section{Conflict of Interests}

None declared

\section{Sponsorship}

The project was funded by the Ministry of Education of Slovakia and the General Secretariat of the Committee of Ministers for Drug Dependencies and Drug Control. Project implementation is one of the activities supporting the fight against drugs and drug addiction in accordance with the national drug strategy. The project is registered under the name: "Cross-sectional study of attitudes, habits and awareness about drugs among primary school children aged 8 to 15 years in Slovakia in the school year 2009/10".

\section{REFERENCES}

1. Blum RW, Nelson-Mmari K. The health of young people in a global context. J Adolesc Health. 2004 Nov;35(5):402-18.

2. World Health Organization. Media centre. Young people: health risks and solutions [Internet]. Geneva: WHO; 2011 [cited 2012 Aug 20]. Available from: http://www.who.int/mediacentre/factsheets/fs345/en/index.html.

3. Koleničová J. The need for intensive drug prevention focused on the school environment. In: Current problems of drug addiction in Slovakia and other EU countries: proceedings; 2010 Apr 27; Bratislava, Slovakia. Bratislava: University of Economics in Bratislava; 2010. p. 32-6. (In Slovak.)
4. Bieliková M, Pétiová M. Drugs and youth lifestyle in the Slovac Republic. Bratislava: The Institute of Information and Prognoses of Education; 2003. (In Slovak.)

5. Nociar A. Final report from the TAD for primary school children, secondary school students and their teachers in 2010 [Internet]. Bratislava: Research Institute of Child Psychology and Patopsychology; 2010 [cited 2012 Jul 14]. Available from: http://www.infodrogy.sk/indexAction.cfm ?module $=$ Library \&action $=$ GetFile $\&$ DocumentID $=845$. (In Slovak.)

6. Nociar A. Surveys on drugs, alcohol and tobacco among youth in Slovakia. Bratislava: Veda; 2004. (In Slovak.)

7. Warren CW, Jones NR, Peruga A, Chauvin J, Baptiste JP, Costa de Silva $\mathrm{V}$, et al.; Centers for Disease Control and Prevention (CDC). Global youth tobacco surveillance, 2000-2007. MMWR Surveill Summ. 2008 Jan 25;57(1):1-28.

8. Marcinkova D, Majdan M, Gergelova P, Rusnak M, Pekarcikova J, Baska $\mathrm{T}$. Socioeconomic predictors of smoking behaviour among school-aged children, in the Slovakia. Bratisl Lek Listy. 2009;110(6):345-9.

9. United Nations Office on Drugs and Crime. Conducting school surveys on drug abuse: Global Assessment Programme on Drug Abuse. Toolkit module 3 [Internet]. New York: United Nations; 2003 [cited $2011 \mathrm{Mar}$ 6]. Available from: http://www.unodc.org/pdf/iran/links/UNODC/ gap toolkit module3.pdf.

10. Goodkind S, Wallace JM, Shook JJ, Bachman J, O'Malley P. Are girls really becoming more delinquent? Testing the gender convergence hypothesis by race and ethnicity, 1976-2005. Child Youth Serv Rev. 2009 Aug 1;31(8):885-95.

11. Bitunjac K, Saraga M. Alcohol intoxication in pediatric age: ten-year retrospective study. Croat Med J. 2009 Apr;50(2):151-6.

12. Bezinović P, Malatestinić D. Perceived exposure to substance use and risk-taking behavior in early adolescence: cross-sectional study. Croat Med J. 2009 Apr;50(2):157-64

13. Toumbourou JW, Hemphill SA, McMorris BJ, Catalano RF, Patton GC. Alcohol use and related harms in school students in the USA and Australia. Health Promot Int. 2009 Dec;24(4):373-82.

14. Weinberg L, Wyatt JP. Children presenting to hospital with acute alcohol intoxication. Emerg Med J. 2006 Oct;23(10):774-6.

15. Woolfenden S, Dossetor D, Williams K. Children and adolescents with acute alcohol intoxication/self-poisoning presenting to the emergency department. Arch Pediatr Adolesc Med. 2002 Apr;156(4):345-8.

16. Currie C, Gabhainn SN, Godeau E, Roberts C, Smith R, Currie D, et al., editors. Inequalities in young people's health: HBSC international report from the 2005/2006 survey. Health policy for children and adolescents, no. 5 [Internet]. Copenhagen: WHO Regional Office for Europe; 2008 [cited 2012 Aug 19]. Available from: http://www.euro.who.int/_data/ assets/pdf file/0005/53852/E91416.pdf.

17. Baška T, Kolarčík P. Risky behaviour in school children: smoking, use of alcohol, marijuana, physical violence. In: Madarasová Gecková A, Katreniaková, Z, Kollárová J, Veselská Z, editors. Social determinants of health of schoolchildren: national report on health and health-related behavior of 11 -, 13 - and 15-year old school children, based on a survey conducted in 2005/2006 in the framework of the international project "Health Behaviour in School Aged Children" (HBSC) [Internet]. Košice: Equilibria; 2009 [cited 2012 Jun 21]. p.53-62. Available from: http:// www.uvzsr.sk/docs/info/podpora/socialne_determinanty_s_obalkou.pdf. (In Slovak.)

18. Australian Government, Department of Health and Ageing. Teenagers and alcohol: a guide for parents [Internet]. Commonwealth of Australia; 2006 [cited 2011 Sep 18]. Available from: http://www.alcohol.gov.au/ internet/alcohol/publishing.nsf/content/4576756CA5268C8ECA25719 400181178/\$File/brochure-teen-alcohol.pdf.

19. Ochaba R, Bielik I. Legal aspects of alcohol control in public health. Lek Obz. 2010; 59(3). (In Slovak.)

20. Donovan JE, Molina BSG. Children's introduction to alcohol use: sips and tastes. Alcohol Clin Exp Res. 2008 Jan;32(1):108-19.

21. Ohannessian CM. Does technology use moderate the relationship between parental alcoholism and adolescent alcohol and cigarette use? Addict Behav. 2009 Jun-Jul;34(6-7):606-9.

22. Hussong AM, Wirth RJ, Edwards MC, Curran PJ, Chassin LA, Zucker RA. Externalizing symptoms among children of alcoholic parents: Entry points for an antisocial pathway to alcoholism. J Abnorm Psychol. 2007 Aug;116(3):529-42.

23. Wong MM, Nigg JT, Zucker RA, Puttler LI, Fitzgerald HE, Jester JM, et al. Behavioral control and resiliency in the onset of alcohol and illicit drug use: a prospective study from preschool to adolescence. Child Dev. 2006 Jul-Aug;77(4):1016-33. 
24. Moore GF, Rothwell H, Segrott J. An exploratory study of the relationship between parental attitudes and behaviour and young people's consumption of alcohol. Subst Abuse Treat Prev Policy. 2010 Apr 22;5:6.

25. Lopez B, Wang W, Schwartz SJ, Prado G, Huang S, Hendricks Brown C, et al. School, family, and peer factors and their association with substance use in Hispanic adolescents. J Prim Prev. 2009 Nov;30(6):622-41.

26. Parsai M, Voisine S, Marsiglia FF, Kulis S, Nieri T. The protective and risk effects of parents and peers on substance use, attitudes and behaviors of Mexican and Mexican American female and male adolescents. Youth Soc. $2009 ; 40(3): 353-76$.
27. Ando M, Asakura T, Ando S, Simons-Morton BG. Psychosocial factors associated with smoking and drinking among Japanese early adolescent boys and girls: Cross-sectional study. Biopsychosoc Med. 2007 Jul 4;1:13. 28. Csémy L, Sovinová H, Procházka B. Alcohol consumption and marijuana use in young adult Czechs. Cent Eur J Public Health. 2012 Dec;20(4):244 7.

Received April 11, 2013 Accepted in revised form October 14, 2013 